\title{
Permian-Triassic mass extinction - a carbon-driven climatic and biogeochemical collapse
}

\author{
DR. HANA JURIKOVA ${ }^{1,2}$, DR. MARCUS GUTJAHR ${ }^{2}$, \\ KLAUS WALLMANN ${ }^{2}$, SASCHA FLÖGEL ${ }^{2}$, VOLKER \\ LIEBETRAU $^{2}$, RENATO POSENATO ${ }^{3}$, LUCIA ANGIOLINI ${ }^{4}$, \\ CLAUDIO GARBELLI ${ }^{3}$, UWE BRAND ${ }^{5}$, MICHAEL \\ WIEDENBECK ${ }^{6}$ AND ANTON EISENHAUER ${ }^{2}$ \\ ${ }^{1}$ University of St Andrews \\ ${ }^{2}$ GEOMAR Helmholtz Centre for Ocean Research Kiel \\ ${ }^{3}$ Università di Ferrara \\ ${ }^{4}$ Università di Milano \\ ${ }^{5}$ Brock University \\ ${ }^{6}$ GFZ German Research Centre for Geosciences \\ Presenting Author:hj43@st-andrews.ac.uk
}

The Permian-Triassic mass extinction (approximately 251.9 million years ago) is the most severe environmental and biotic crisis identified in the geological record that marked the turning point for evolution of life on Earth. To date, however, its exact causes and consequences still remain highly controversial. Magmatism from the large igneous province (LIP) Siberian Traps was contemporaneous with the extinction and is thought to have played an important role, however, how a long-lived LIP could have led to such a sudden and rapid catastrophe of the observed magnitude has been challenging to reconcile. Combining new boron isotope-derived seawater $\mathrm{pH}$ estimates, global carbon isotope records and innovative geochemical modelling, we present a comprehensive biogeochemical reconstruction which illuminates the underlying mechanisms that resulted in the largest Phanerozoic mass extinction. We show that a LIP intrusion into organic-rich sediments led to an unprecedented $\mathrm{CO}_{2}$ release to the atmosphere, setting off a chain of profound climatic and chemical changes that ultimately made a large part of the oceans inhospitable to life [1].

[1] Jurikova H., et al. (2020), Nature Geoscience 13, 745-750, https://doi.org/10.1038/s41561-020-00646-4. 